Sharif University of Technology
Scientia Iranica
Transactions C: Chemistry and Chemical Engineering
w
I RANw.scientiairanica.com

\title{
Experimental study of rheological properties of aphron based drilling fluids and their effects on formation damage
}

\author{
M. Heidari ${ }^{a}$, Kh. Shahbazi ${ }^{a, *}$ and M. Fattahi ${ }^{b}$ \\ a. Department of Petroleum Engineering, Ahwaz Faculty of Petroleum Engineering, Petroleum University of Technology, Abadan, \\ Iran. \\ b. Department of Chemical Engineering, Abadan Faculty of Petroleum Engineering, Petroleum University of Technology, Abadan, \\ Iran.
}

Received 16 September 2015; received in revised form 31 December 2016; accepted 4 March 2017

\author{
KEYWORDS \\ Drilling fluid; \\ Polymer-surfactant; \\ CGA; \\ Rheological \\ properties; \\ Bubble size \\ measurement.
}

\begin{abstract}
Drilling fluid is one of the most important and expensive aspects of any drilling process. Colloidal Gas Aphron (CGA) has been found effective in controlling the filtration rate by bridging the pores of the reservoir rock; hence, reducing the formation damage. This work aims to synthesize the CGA in water based drilling fluids to study the stability, rheology, filtration loss characteristics and formation damage properties of the resulting fluid. Besides, an investigation on type of polymer, surfactant, and their concentration effects on the characteristics of the fluid, as well as optimum ratios of polymers in drilling fluid was performed. Experimental results showed that Xanthan Gum (XG) provides more acceptable rheological properties (especially viscosity) in comparison to Guar Gum (GG) for preparing the base fluid. Moreover, the Sodium Dodecyl Sulfate (SDS) produces more stable micro-bubbles than Hexadecyl Trimethyl Ammonium Bromide (HTAB) as a surfactant. Bubble size measurement to observe the effect of polymer, surfactant type and concentration was performed. Through the experiments, the $\mathrm{pH}$ of the drilling fluid was monitored which proved the CGA introduced the best performance around a $\mathrm{pH}$ of 9 . Furthermore, a XG/GG ratio of 3:1 is suggested to reduce the cost while maintaining the fluid properties.
\end{abstract}

(C) 2017 Sharif University of Technology. All rights reserved.

\section{Introduction}

When a well is drilled, the pressure in the wellbore is usually kept above the pressure in the formation to prevent formation fluids entering the well. This is called overbalanced drilling (OBD) and has several limitations. It can cause formation damage when the drilling mud is forced into the formation (fluid invasion). Large amounts of the drilling mud can be

\footnotetext{
* Corresponding author.

E-mail addresses: meraj.heydari.68@gmail.com ( $M$. Heidari); shahbazi@put.ac.ir (Kh. Shahbazi); fattahi@put.ac.ir (M. Fattahi)
}

uncontrollably lost into the formation (lost circulation). Differential sticking is also a problem associated with OBD. Underbalanced drilling (UBD) as an alternative to OBD can overcome these issues while UBD, the wellbore pressure, is maintained lower than the formation pressure. The primary advantage of UBD is preventing fluid invasion and the resultant formation damage. It also helps the reduction of differential sticking and increasing the rate of penetration. However, UBD is an expensive task and meeting the safety requirements is not easy. A lot of problems like borehole instability, well control, and use of special downhole equipment come up [1]. At-balance drilling means drilling with the wellbore fluid pressure closely matching the formation 
fluid pressure so that there is minimal fluid invasion and the formation fluids do not come into the wellbore. In an at-balance situation, use of CGA based drilling fluids helps to produce lower drilling fluid densities and to seal the pores by bridging [2]. Such a system can be particularly useful in drilling depleted and low pressure reservoirs.

Aphrons are colloidal dispersions of micro-bubbles with diameters ranging from 10 to $100 \mu \mathrm{m}$ [3]. An aphron is made of a core, which is often a spherical internal phase, encapsulated in a thin shell. In case of a gaseous core, this structure is called CGA [3]. When the internal core is a liquid, normally oil based, it is called colloidal liquid aphron [4]. Finally, the aphrons with cores formed of water-in-oil emulsion are called colloidal emulsion aphrons [5]. Todays, the use of CGA based fluids is increasing in the petroleum industry because these fluids exhibit properties that are desirable in operations in many fields [1,2,6-9]. The potential of aphrons as components of drilling fluids is due to their ability to form a solid, free, tough, and elastic internal bridge in pore networks or fractures to minimize deep invasion through air microbubbles [10,11]. Moreover, the high carrying capacity, minimum amount of fluid placed in the formation, and good fluid recovery after treatment are some of the advantages that CGA based fluids utilized during the operations $[2,12,13]$.

CGAs incorporated into drilling mud to form a CGA drilling fluid have been studied extensively, too. Brookey [2] suggested the use of CGA drill-in fluid while drilling at balance. Growcock [14] made a detailed investigation into increasing wellbore stabilization and reservoir productivity by using aphron drilling fluid technology. Aphron based drilling fluids are non-coalescing and can be re-circulated [2] without being affected by downhole equipment. Downhole tools such as MWD, turbines, and motors do not suffer interference by aphrons [15].

CGAs can be produced easily on the surface and no separate equipment like compressors are required to inject gases at high pressure. In UBD, the presence of air creates a condition of extreme corrosion where air and water are in constant contact with the drill string [2]. Corrosion problems are reduced with aphronized fluids due to the fact that most of the air is encapsulated in the aphron shell. Besides, it is common to add an oxygen scavenger to the drilling fluid formulation [14]. Thus, after the aphrons are created, the oxygen is scavenged by one of the components in the fluid, leaving the aphrons with a core of nitrogen [14]. This gives aphrons the non-corrosive nature. Subsequently, the usefulness of aphrons for different types of applications has been suggested.

For stability of the CGA, the concentration of the surfactant should be greater than the Critical Micelle
Concentration (CMC) [16,17], which varies for each type of surfactant. When a concentration of less than the CMC is used, the CGAs will be large in size [17]. CMC measuring could be achieved through surface tension measurements. At the $\mathrm{CMC}$ and beyond, the surface tension will no longer change with concentration. The CMC for some of the surfactants utilized to build CGAs has been reported in the literature. For example, the CMC of HTAB in water is approximately $350 \mathrm{ppm}$ and for sodium dodecyl benzene sulfonate is about $500 \mathrm{ppm}$ [16]. The surface activity and aggregation behavior of the surfactant affect the stability and other physico-chemical properties of the generated micro bubbles in CGA. Therefore, selection of a suitable surfactant is important for the generation of micro bubbles with the desired rheological and filtration properties [18].

The purpose of a surfactant is to be adsorbed at the interface, thereby reducing surface tension. The utilization of tergitol and lauryl alcohol as surfactants for CGA generation was investigated by Sebba [3]. Amiri and Woodburn [19] used a cationic Tetradecyl Trimethyl Ammonium Bromide (TTAB) surfactant for aphron generation. Roy et al. [16] tested an anionic surfactant Sodium Dodecyl Benzene Sulfonate (SDBS) and a cationic surfactant of HTAB. Save et al. [20] used 4 cationic surfactants: Dodecyl Trimethyl Ammonium Chloride (DTAC), Cetyl Trimethyl Ammonium Chloride (CTAC), Cetyl Pyridinium Chloride ( $\mathrm{CPC}$ ), and dimethyl distearyl ammonium chloride (DMDSAC). Save et al. [20] also tested anionic SDBS and Sodium Lauryl Sulfate (SLS). Chaphalkar [21] used tergitol 15-S-12 as a non-ionic surfactant, SDBS as the anionic surfactant, and HTAB as the cationic surfactant. Hashim et al. [22,23] utilized the dilute SDS and Benzyl Dimethyl Hexadecyl Ammonium chloride (BDHA) for aphron generation. Bjorndalen and Kuru [24] used SDBS and HTAB as surfactants for their study on CGAs. Dai and Deng [25] tried hexadecyltrimethyl ammonium chloride (HTAC) as the surfactant. The generation of aphrons in oil and its detailed formulation were investigated by Growcock et al. [11]. However, they did not give any specific information as to what type/class of surfactant was used.

Xanthan Gum (XG) polymer, a high-molecularweight natural polysaccharide, is a common drilling fluid additive for controlling fluid loss and viscosity improvement in the formulation of both oil-based and water-based drilling muds [26,27]. It hydrates rapidly in cold water without lumping to give a reliable viscosity and use it as a thickener, stabilizer, emulsifier, and foaming agent [28]. It has tolerance to changes of temperature, acidity, and alkalinity. From the viewpoint of environmental concerns, XG presents good properties for drilling mud applications [29]. Furthermore, a critical concentration of 1.25 to $1.5 \mathrm{lb} / \mathrm{bbl}$ must be 
present in the formulation of a drilling fluid to provide adequate cutting transport capacity [26]. Bjorndalen and Kuru [24] prepared aphron fluids with a water-XG mixture as a base fluid. They used the XG biopolymer as a viscosifier and aphron stabilizer. Spinelli et al. [30] prepared the base fluids for aphronization by mixing the organic phase at different concentrations of organophilic clay and viscosifiers.

From laboratory and field tests it has been found that the combination of two major factors, i.e. drilling fluid and rheology, has greater effect on the rate of penetration than any other controllable variables in the drilling process [31]. In spite of the documented literature on the physicochemical characteristics and rheological behavior of CGA based drilling fluids [3243], the interpretation of the rheological model of CGA based drilling fluids has not been fully addressed. Amiri and Woodburn [19] found the average size of the micro bubbles to be $35 \mu \mathrm{m}$ by analyzing through optical microscope. Feng et al. [44] took microscopic photographs of the bubbles. The pictures were analyzed using an image analysis tool pack to obtain the bubble size distribution. About 100-300 bubbles were counted for each sample. Zhao et al. [45] measured 130 to 240 individual bubbles using image analysis software and a microscope. Spinelli et al. [30] used a similar microscope and image analysis software combination to work on the size distribution.

Brookey [2] presented four case studies, where aphron fluids were applied successfully. The first application was in West Texas, where a horizontal reentry well was drilled. In the second application, in a dolomitic zone in North Texas where severe lost circulation due to large openings existed, the use of aphron fluids made it possible to drill with no losses. In the third application, in a shale formation, the High Yield Stress Shear Thinning (HYSST) nature of the aphron fluids made it possible to control invasion while providing borehole stability. In the fourth and last applications, in a sisquoc sand well (unconsolidated permeable sand) aphron HYSST, drilling fluid provided invasion control and avoided instability that might be encountered in sand wells. MacPhail et al. [46] described several case studies of wells in Alberta and Mississippi. Aphron fluid technology was successfully applied in several completion and workover applications leading to reduced fluid loss. Rea et al. [8] used aphron fluids as a workover fluid in the Tajin field in Eastern Mexico that the bridging provided by aphrons, leading to effective sealing.

The aim of this study was to investigate aphron based drilling fluid's unique characteristics and physicochemical properties. Rheological behavior and stability of the prepared aphronized drilling fluids were also studied. API filtration loss, which is a key indication in evaluating the performance of aphronized fluids in pre- venting filtrate from entering into the formation rock and consequently minimizing formation damage, was investigated. Effects of polymer, surfactant type, and concentration were also monitored. Furthermore, the main objective was to achieve proper formulation and optimization of CGA characteristics and properties. The ability of the surfactant in the reduction of density and polymer performance in enhancing the toughness of aphrons, and the effect of $\mathrm{pH}$ on CGA characteristics and performance with regard to its influence on polymer based mud were studied. Moreover, the rheological characteristics and properties of a system containing stable micro bubbles and the bubble size distribution of aphronized fluid were investigated in this research.

\section{Experimental}

\subsection{Materials and methods}

To produce aphron in aqueous medium, distilled water was utilized as the base liquid for aphron. The CGA fluid in this study was composed of two main materials: polymer and surfactant. The utilized polymers in this study were XG and GG supplied by MI SWACO \& SCOMI Oil Tools, respectively. According to the literature, $\mathrm{XG}$ is the most effective viscosifier for aphron based fluid; however, the effect and performance of GG were investigated in this research.

Cationic and anionic surfactants were used to produce the CGA. Two types of surfactants were chosen for the production of the CGA: HTAB as a cationic surfactant and SDS as an anionic surfactant. These surfactants were chosen based upon the previous research $[16,47]$. In this work, we focused on the anionic surfactant, i.e. SDS. SDS or SLS with the formula $\mathrm{C}_{12} \mathrm{H}_{25} \mathrm{SO}_{4} \mathrm{Na}$ is an anionic surfactant made up of an organosulfate consisting of a 12-carbon tail attached to a sulfate group. A mud mixer was used to mix the drilling fluid components. All mixing was performed by a Hamilton Beach mixer. The density of the fluid was measured using either a mud balance or, in the case where the density was low, a digital scale and fixed fluid volume was used. To determine acidity or alkalinity of solutions, a $\mathrm{pH} / \mathrm{mV}$ meter automatic temperature compensation AZ brand, model 8601, was used. To control and compensate the $\mathrm{pH}$ of the solution in range, caustic soda and citric acid were added to increase and decrease the $\mathrm{pH}$, respectively.

During all steps, an OFITE VG meter, Fann model $35 \mathrm{~A}$, to obtain rheological properties was utilized. This type of VG meter acted as a heater, so temperature was under control according to well conditions; also, continuous monitoring was possible by the thermometer, which was attached to the main cap. The rotational viscometer was developed for quantitative and more accurate readings of the viscosity. The dimensions of bob and rotor were chosen such that the 
dial reading on the viscometer was equivalent to the apparent viscosity in centipoises at a rotor speed of $300 \mathrm{rpm}$. The apparent viscosities were calculated as:

$$
\mu_{a}=\frac{300 \theta_{N}}{N}
$$

where, $\theta_{N}$ is the dial reading in degrees, and $N$ is the rotor speed in rpm. The apparent viscosity, plastic viscosity, and yield point were calculated from 300 and $600 \mathrm{rpm}$ readings using the following formulae from the API recommended practice of standard procedure for field testing drilling fluids:

$$
\begin{aligned}
& \mu_{p}=\theta_{600}-\theta_{300} \\
& \tau_{y}=\theta_{300}-\mu_{p}
\end{aligned}
$$

where, $\mu_{p}$ is the plastic viscosity in centipoises, and $\theta_{600}$ and $\theta_{300}$ are the dial readings at $600 \mathrm{rpm}$ and $300 \mathrm{rpm}$, respectively. $\tau_{y}$ is the yield point in $\mathrm{Ib}_{\mathrm{f}} / 100$ sq ft. Based on the rheology theory of power law fluid, the consistency coefficient and the behavior index of drilling fluid were calculated from 300 and $600 \mathrm{rpm}$ readings using the following formulae:

$$
K=\frac{0.51 \theta_{300}}{511^{n}} .
$$

For behavior index:

$$
n=3.322 \log \left(\frac{\theta_{600}}{\theta_{300}}\right),
$$

where $K$ is the consistency index in dyne.s $\mathrm{s}^{\mathrm{n}} / \mathrm{cm}^{2}$ and $n$ is the flow behavior index. Standard API filtration tests were done using a standard API filter press to determine filtration volume as a key indicator to determine the amount of fluid invasion toward formation and its related formation damage. The equipment was supplied by OFITE testing equipment Inc. (MI SWACO mud lab. on a Jack Up Rig). The standard API filter press had an area of $45 \mathrm{~cm}^{2}$ and the tests were operated at a pressure of $100 \mathrm{psig}$ and room temperature of about $75^{\circ} \mathrm{F}$. The filtrate volume collected in a period of $30 \mathrm{~min}$ was reported as standard water loss.

In this study, the micro bubble samples were imaged immediately following the aphron generation process by using a Sony ExwaveHAD digital video camera attached to a SaIran IMM-420 microscope with a high degree of magnification. The aim was to observe the effect of biopolymer and surfactant type as well as concentration and sizes of micro bubbles.

\subsection{Preparation of aphronized based fluid}

Polymers including XG (from 0 to $2 \mathrm{lb} / \mathrm{bbl}$ ) and $\mathrm{GG}$ (from 0 to $2 \mathrm{lb} / \mathrm{bbl}$ ) were added to water in order to prepare the base fluid. The base fluid was generated by smoothly mixing the appropriate amount of polymer with $350 \mathrm{~mL}$ of distilled water for production of aphron. To monitor and control the effect of $\mathrm{pH}$ (at 5, 9, and 12), additives (i.e., caustic soda and citric acid) were added to the base water in order to convert the media to an alkaline or acidic environment. The solutions were agitated for 20 min, starting with a low speed of $3000 \mathrm{rpm}$ and gradually increasing the speed to a maximum of $8000 \mathrm{rpm}$, to avoid formation of local viscosified agglomerates, which are known as "fish eyes". Moreover, a micro bubble suspension was easily generated using a spinning disc type generator with a surfactant solution [48]. During preparation of the base fluid, the temperature of the mixture may increase due to mixing which may cause instability in the micro bubbles, so it is recommended to wait around $5 \mathrm{~min}$ for the mixture to adapt to room temperature. Next, the surfactants including $\operatorname{SDS}(0.5$ and $0.75 \mathrm{lb} / \mathrm{bbl})$ and $\operatorname{HTAB}(0.5$ and $0.75 \mathrm{lb} / \mathrm{bbl})$ were gently mixed at $3000 \mathrm{rpm}$; then, the speed increased to $8000 \mathrm{rpm}$ within $2 \mathrm{~min}$. The stability and rheological properties of CGA were influenced not only by the average size of the bubbles but also by the bubbles size distribution. Microscope-assisted photographic techniques are the most common methods for bubble size determination. Time is crucial in this technique because, under static conditions, the size and shape of the bubbles change due to diffusion problems. To minimize these problems, the micro bubble samples were imaged immediately following the aphron generation process. Aphronized drilling fluids are compressible non-Newtonian fluids and behave like yield pseudo-plastic type fluids with shear thinning characteristics [40].

\section{Results and discussion}

Rheology, bubble size distribution, density, and filtration loss of aphronized fluids were investigated using different types of polymers and surfactants.

\subsection{Effect of rheology}

Rheological properties of aphronized fluids generated from two types of anionic and cationic surfactants are summarized in Table 1. Compared to the base fluid, both SDS and HTAB were able to improve plastic viscosity and yield point. Results indicated that by increasing surfactant concentration, rheological properties improved for both surfactants, while SDS demonstrated better performance. This means SDS generates more micro-bubbles due to better rheological properties. In other words, by adding the same amount of surfactants (i.e., 0.5 and $0.75 \mathrm{lb} / \mathrm{bbl}$ to $2 \mathrm{lb} / \mathrm{bbl}$ of XG solution), the aphronized fluid prepared by SDS reveals more desirable properties than HTAB. 
Table 1. Effect of surfactant type and concentration on rheological properties of CGA fluid prepared by $2 \mathrm{lb} / \mathrm{bbl} \mathrm{XG}$ solution.

\begin{tabular}{cccccc}
\hline Fluid & $\begin{array}{c}\text { Surfactant } \\
\text { concentration }\end{array}$ & AV & PV & YP & $\begin{array}{c}\text { GS } \\
\text { (10 sec/10 min) }\end{array}$ \\
\hline Base fluid & 0 & 23.5 & 10 & 27 & $14 / 16$ \\
Base fluid + SDS & 0.5 & 58 & 26 & 64 & $22 / 30$ \\
Base fluid + HTAB & 0.75 & 64.5 & 28 & 73 & $23 / 32$ \\
& 0.5 & 30.5 & 16 & 29 & $16 / 18$ \\
& 0.75 & 34 & 17 & 33 & $17 / 19$ \\
\hline
\end{tabular}

Furthermore, the data proved that by increasing surfactant concentration, the yield point increased drastically (especially for SDS, which increased from 64 for $0.5 \mathrm{lb} / \mathrm{bbl}$ to 73 for $0.75 \mathrm{lb} / \mathrm{bbl}$ ) while plastic viscosity remained nearly constant (16 at $0.5 \mathrm{lb} / \mathrm{bbl}$ and 17 for $0.75 \mathrm{lb} / \mathrm{bbl}$ for HTAB PV). Both surfactants were able to increase the gel strength of the base fluid, but different concentrations of the surfactant had little effect on gel strength. Overall, adding a surfactant improved the rheological properties of aphron based fluids and increasing surfactant concentration improved these properties due to the generation of more stable bubbles.

In order to observe the pH effect on CGA rheology, citric acid and caustic soda were added to the base water to produce an acidic and alkaline environment. Aphronized fluid was prepared with a $2 \mathrm{lb} / \mathrm{bbl} \mathrm{XG}$ and $0.75 \mathrm{lb} / \mathrm{bbl}$ SDS solution. The results of $\mathrm{pH}$ effects on rheology are illustrated in Table 2.

By adding the proper amount of citric acid or caustic soda, $\mathrm{pH}$ of the solution was controlled around 5 and 12 , respectively, while the $\mathrm{pH}$ of the base fluid was 7 due to the distilled water, which was used to make the solution. The data in Table 2 shows that plastic viscosity decreases slightly in an acidic or basic environment, but the environment has no significant effect on yield

Table 2. Effect of $\mathrm{pH}$ on rheological properties of CGA fluid prepared by $2 \mathrm{lb} / \mathrm{bbl} \mathrm{XG}$ and $0.75 \mathrm{lb} / \mathrm{bbl}$ SDS solution.

\begin{tabular}{ccccc}
\hline pH & AV & PV & YP & $\begin{array}{c}\text { GS } \\
\text { (10sec/10min) }\end{array}$ \\
\hline 5 & 60.5 & 24 & 73 & $22 / 33$ \\
9 & 67 & 30 & 74 & $24 / 34$ \\
12 & 62 & 25 & 74 & $21 / 32$ \\
\hline
\end{tabular}

point. In other words, plastic viscosity shows the most changes with regard to different media. Moreover, gel strength remained nearly constant for the different $\mathrm{pH}$. It was observed that better rheological performance occurred when the $\mathrm{pH}$ of the base fluid was around 9. Overall, the $\mathrm{pH}$ value had no very significant effect on the mean size, stability, and rheological properties of bubbles. In the $\mathrm{pH}$ ranges over 7 , the SDS surfactant in the solution was present mainly in the anionic form, which was confirmed by the open literature [49]. The electrostatic interactions of the ionic form of the surfactant contributed to the stability of CGA, which was consistent with observations reported by Jauregi et al. [50]. The results showed that the viscosity of CGA solution was low as it had fluidity and could be easily separated from the bulk liquid phase.

Effect of polymer type and concentration on rheological properties of aphronized fluids prepared by $0.75 \mathrm{lb} / \mathrm{bbl}$ SDS is summarized in Table 3. Previous research efforts [51] have been focused on the acceptable rheological properties of XG; however, the practical use of XG is limited due to its high cost. Therefore, to give the desired rheological properties, GG was added in different proportions as an alternative to reduce the cost.

Based on Table 3, the performance of $\mathrm{XG}$ was better than that of GG, as was expected.

To draw shear stress versus shear rate, there are some relationships due to bob and rotor dimensions (i.e., radius and length), which are as follows:

$$
\begin{gathered}
\tau=\frac{360.5 \theta}{2 \pi h r^{2}} \\
\gamma=\frac{5.066 N}{r^{2}}
\end{gathered}
$$

\begin{tabular}{|c|c|c|c|c|c|}
\hline \multicolumn{2}{|c|}{ Additives } & \multirow[b]{2}{*}{ AV } & \multirow[b]{2}{*}{$\mathbf{P V}$} & \multirow[b]{2}{*}{ YP } & \multirow{2}{*}{$\begin{array}{c}\text { GS } \\
(10 \mathrm{sec} / 10 \mathrm{~min})\end{array}$} \\
\hline $\begin{array}{c}\mathrm{XG} \\
(\mathrm{lb} / \mathrm{bbl})\end{array}$ & $\begin{array}{c}\text { GG } \\
(\mathrm{lb} / \mathrm{bbl})\end{array}$ & & & & \\
\hline 2.0 & 0.0 & 64 & 28 & 73 & $23 / 33$ \\
\hline 1.5 & 0.5 & 63 & 27 & 72 & $21 / 30$ \\
\hline 1.0 & 1.0 & 57.5 & 23 & 69 & $19 / 23$ \\
\hline 0.5 & 1.5 & 53.5 & 21 & 65 & $17 / 20$ \\
\hline 0.0 & 2.0 & 45 & 21 & 48 & $14 / 18$ \\
\hline
\end{tabular}

Table 3. Effect of polymer type and concentration on rheological properties of CGA prepared by $0.75 \mathrm{lb} / \mathrm{bbl} \mathrm{SDS}$. 
where, $r=1.7245$ and $h=3.8$ for Fann 35A.

The shear stress versus shear rate was presented in Figure 1(a) to (c) based upon the reading data of $\theta$. The addition of GG to XG reduced the quality of the aphronized fluid. However, as Figure 1(c) presents, when they were mixed in a ratio of 3 to 1 , the rheology did not change significantly. This could reduce the final cost of drilling fluid while maintaining the quality at the same level.

\subsection{Effect of bubble size distribution}

Average bubble diameter and size distribution of aphrons are very important factors, which affect the

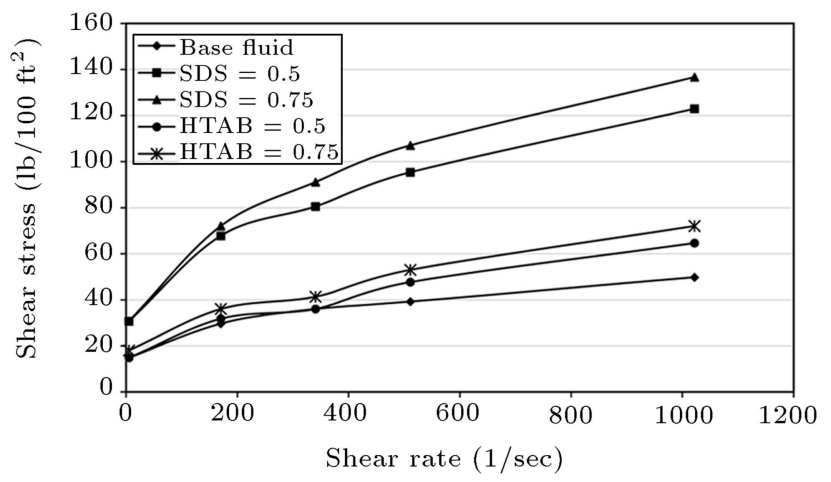

(a)

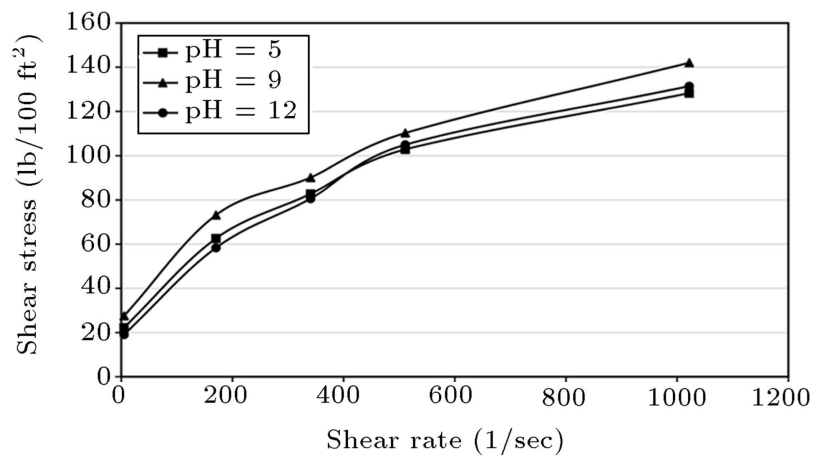

(b)

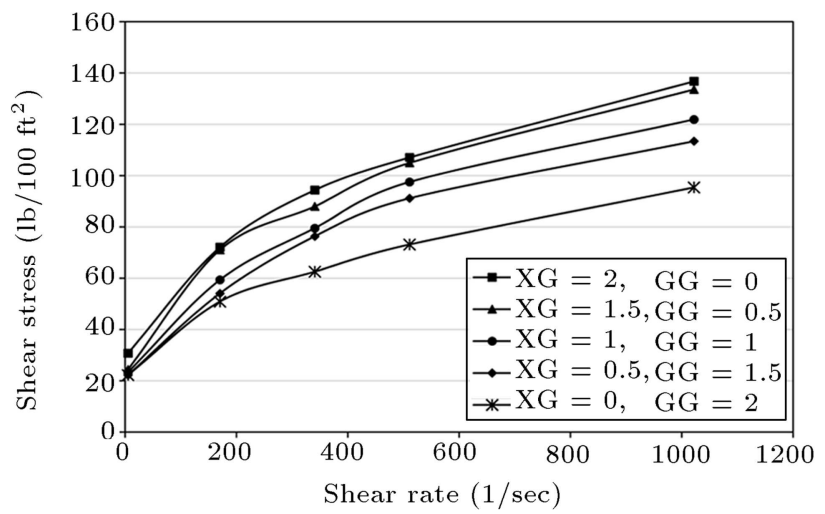

(c)

Figure 1. Effect of (a) surfactant type and concentration, (b) $\mathrm{pH}$, and (c) polymer type and concentration on rheological properties of the prepared CGA fluid. pore bridging and blockage mechanism. Bubble size distribution is one of the indicators that reflect the quality of the generated aphron. Immediately after preparation of the CGA fluid, a small sample of fluid was taken for imaging and size measurements. In these experiments, the base water $\mathrm{pH}$ was set at 9 , where the best rheology performance was obtained. Figure 2 shows two microscopic pictures taken from aphronized fluids prepared by SDS and HTAB surfactants (with $0.75 \mathrm{lb} / \mathrm{bbl}$ concentration) while the base fluid was composed of water and $2.0 \mathrm{lb} / \mathrm{bbl} \mathrm{XG}$ as the polymer. "Golden Ratio" software (Version 3.1.2) was used to measure the size of the bubbles. In order to measure the bubble size, a line with a specified length was given to the software. The lengths as well as the angle and the ratio of the two lines were displayed.

Table 4 illustrates the effect of surfactant type and concentration, polymer concentration, and $\mathrm{pH}$ on the average bubble size of CGA fluids. Results show that by increasing the surfactant concentration, the

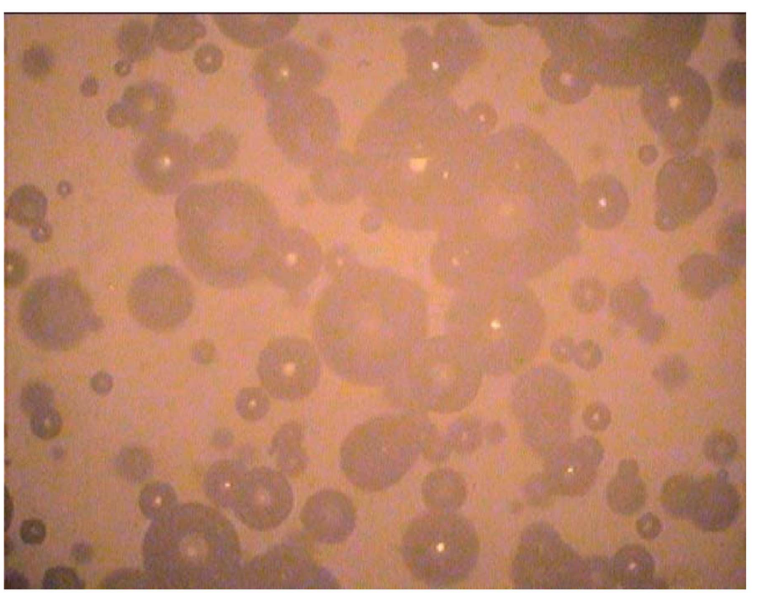

(a)

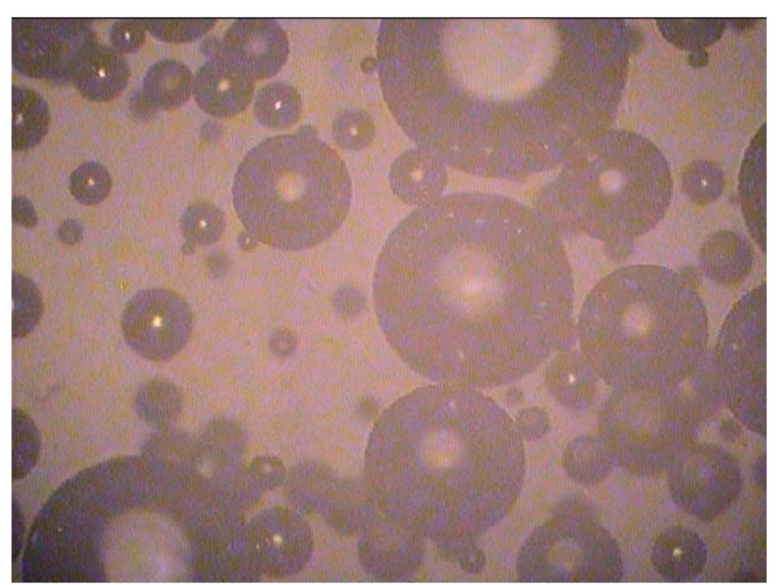

(b)

Figure 2. Microscopic picture of aphron micro bubbles from (a) $0.75 \mathrm{lb} / \mathrm{bbl}$ SDS and (b) $0.75 \mathrm{lb} / \mathrm{bbl} \mathrm{HTAB}$ solutions at concentration of $2 \mathrm{lb} / \mathrm{bbl} \mathrm{XG}$. 
Table 4. Effect of surfactant type and concentration, polymer concentration, and pH on average bubble size.

\begin{tabular}{ccccc}
\hline \multirow{2}{*}{$\begin{array}{c}\text { Aurfactant } \\
\text { type }\end{array}$} & $\begin{array}{c}\text { Surfactant } \\
\text { concentration } \\
\text { (lb/bbl) }\end{array}$ & $\begin{array}{c}\text { Polymer } \\
\text { concentration } \\
(\mathbf{l b} / \mathbf{b b l})\end{array}$ & pH & $\begin{array}{c}\text { Average bubble } \\
\text { size }(\boldsymbol{\mu m})\end{array}$ \\
\hline SDS & 0.5 & 2 & 9 & 79 \\
SDS & 0.75 & 2 & 9 & 77 \\
SDS & 1 & 2 & 9 & 65 \\
SDS & 0.5 & 1.5 & 9 & 84 \\
SDS & 0.5 & 2.5 & 9 & 67 \\
SDS & 0.75 & 2 & 5 & 81 \\
SDS & 0.75 & 2 & 12 & 80 \\
HTAB & 0.75 & 2 & 9 & 84 \\
\hline
\end{tabular}

average bubble size decreases. One reason could be the availability of more surfactant molecules to generate viscous shells, which resulted in the generation of more micro bubbles and a reduction in average bubble sizes. On the other hand, by increasing the polymer concentration, the average bubble size decreased. Increasing polymer concentration caused the base fluid viscosity to increase and reduced the shear stress exerted on the fluid by the spinner. Therefore, the size of aphrons was reduced. Table 4 shows that acidic or alkaline environments led to higher average bubble sizes, which could be a result of lower viscosity in those conditions (Table 4). Nonetheless, as Table 4 reflects, CGA fluid generated from HTAB had higher average bubble sizes than the one prepared by SDS.

The effect of polymer concentration on bubble size distribution can be seen in Figure 3, which shows the average bubble size in the aphron based fluid with $\mathrm{XG}$ as the polymer in concentrations of 1.5, 2.0, and $2.5 \mathrm{lb} / \mathrm{bbl}$ and SDS as the surfactant with concentration of $0.5 \mathrm{lb} / \mathrm{bbl}$. Comparing Figure 3(a) and (c), it is clear that by increasing polymer concentration, the fraction of small-diameter bubbles increases significantly. In other words, if we increase polymer concentration from 1.5 to $2.5 \mathrm{lb} / \mathrm{bbl}$, the peak of size distribution graph will shift from $60-80$ to $40-60 \mu \mathrm{m}$, which results in lower average bubble sizes.

The fraction of bubbles with small diameters enhanced as the surfactant concentration was increased. This fact was obtained at $2.0 \mathrm{lb} / \mathrm{bbl}$ of $\mathrm{XG}$ as the polymer while the $\mathrm{pH}$ was controlled around 9 and the concentration of SDS as the surfactant was increased from $0.5 \mathrm{lb} / \mathrm{bbl}$ to $1.0 \mathrm{lb} / \mathrm{bbl}$, gradually. Moreover, the effect of surfactant type is presented in Figure 4, with the same concentrations of polymer $(2.0 \mathrm{lb} / \mathrm{bbl})$ and surfactant $(0.75 \mathrm{lb} / \mathrm{bbl})$. Besides, SDS is able to produce smaller micro bubbles than HTAB. This shows that SDS performed better in generating the aphronized fluids.
The effect of base water $\mathrm{pH}$ on size distribution of aphron bubbles indicated that in acidic and extremely basic environments, a wide range of micro bubbles were formed in comparison with the situation where $\mathrm{pH}$ was kept around 9 . In other words, when $\mathrm{pH}$ fluctuated around 9, average bubble sizes varied both up and down and their distribution was affected, which led to lower quality.

\subsection{Effect of density}

The density of CGA fluid shows the quantity of micro bubbles and the potential of the surfactant to form aphrons. The effect of surfactant concentration on density has been studied in several investigations [52]. It has been shown that increasing surfactant concentration might reduce the density of aphronized fluid due to the increase in the number of micro bubbles formed. The effect of polymer concentration has also been investigated in the previous research, which shows that higher polymer concentrations result in higher densities.

The effects of two different types of surfactants (an anionic (SDS) and a cationic (HTAB) surfactant) and their concentrations on the density of aphronized fluid are indicated in Figure 5. As it is shown, adding surfactant reduces solution density that is obvious due to the formation of micro bubbles. It might be concluded from Figure 5 that SDS reduces the density of CGA more than HTAB does. This indicates that SDS is able to generate more micro bubbles than HTAB does at the same concentration. SDS at $0.75 \mathrm{lb} / \mathrm{bbl}$ of concentration reduced the density of $2 \mathrm{lb} / \mathrm{bbl} \mathrm{XG}$ base fluid from 61 to $25 \mathrm{pcf}$, whereas HTAB, at the same concentration, reduced the density to 34 pcf.

The effect of polymer type on the density of CGA fluid is shown in Figure 6. This figure indicates that the CGA prepared with XG base fluid provided low density compared to CGA derived from GG. This observation reconfirms the above-mentioned rheology 


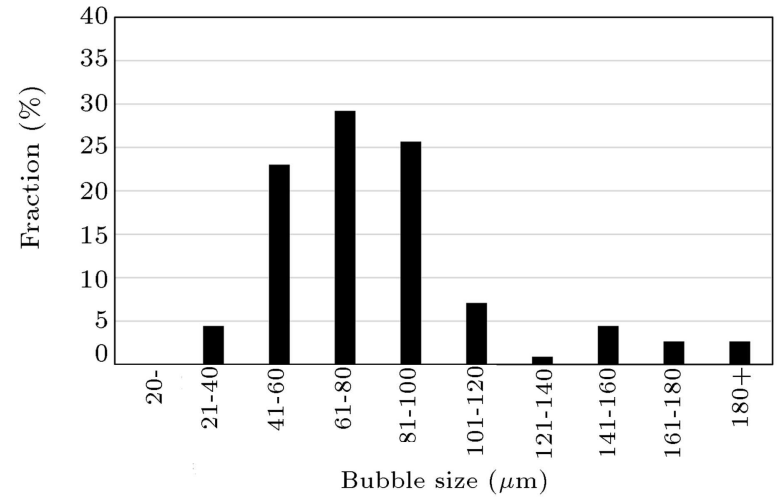

(a)

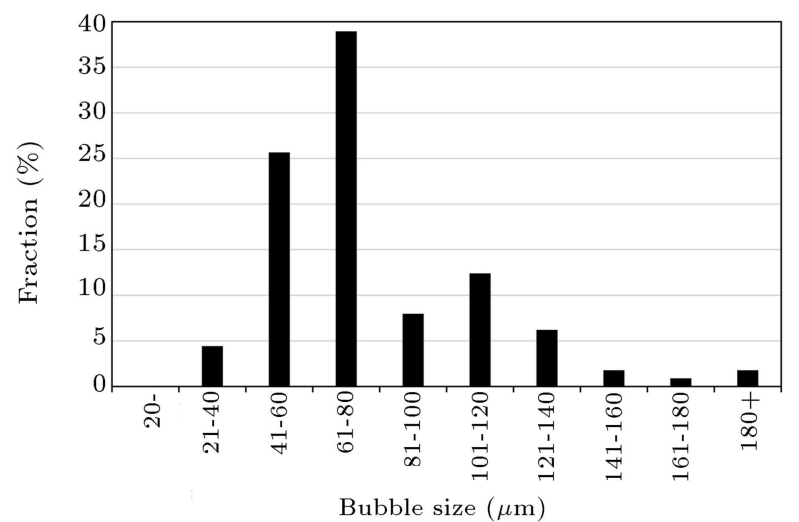

(b)

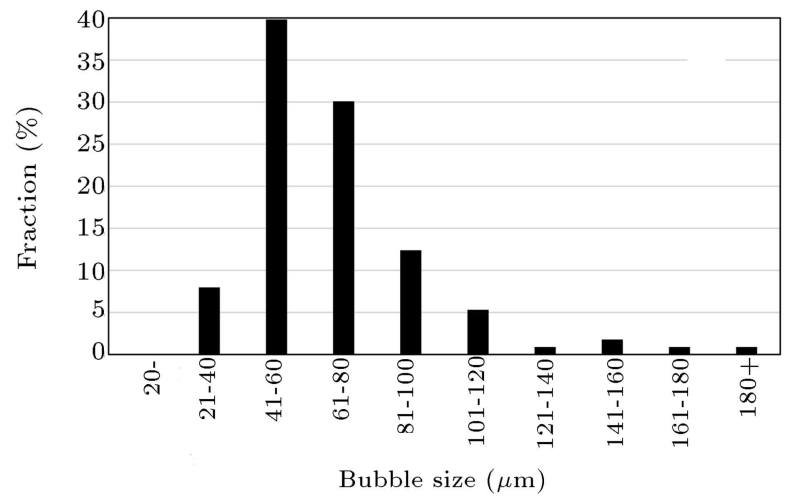

(c)

Figure 3. Bubble size distribution of the prepared CGA fluid by (a) $1.5 \mathrm{lb} / \mathrm{bbl} \mathrm{XG,} \mathrm{(b)} 2.0 \mathrm{lb} / \mathrm{bbl} \mathrm{XG}$, and (c) $2.5 \mathrm{lb} / \mathrm{bbl} \mathrm{XG}$ and $0.5 \mathrm{lb} / \mathrm{bbl}$ SDS.

results, where XG provided better rheological properties than GG did. Therefore, CGA fluid derived from $\mathrm{XG}$ is able to generate more stable micro bubbles and reduces density of the solution. It should be pointed out that the density measurements were taken under atmospheric pressure conditions. As pressure increases (e.g., in downhole conditions), the aphrons will be compressed and the density of fluid increases.

\subsection{Filtration control effect}

Filtration loss control is one of the most important

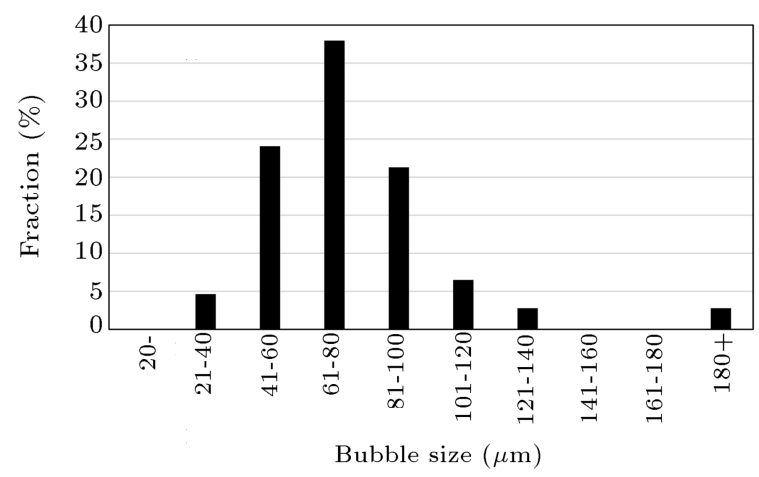

(a)

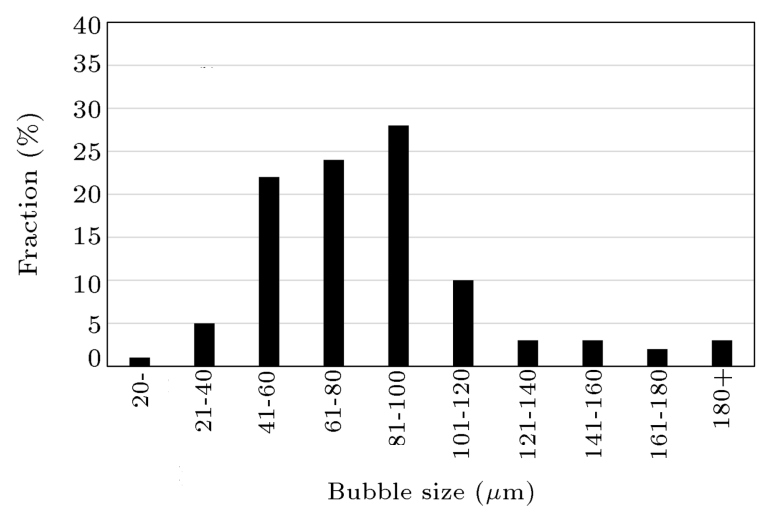

(b)

Figure 4. Bubble size distribution of the prepared CGA fluid by $2 \mathrm{lb} / \mathrm{bbl}$ XG and different surfactants of (a) $0.75 \mathrm{lb} / \mathrm{bbl}$ SDS and (b) $0.75 \mathrm{lb} / \mathrm{bbl}$ HTAB.

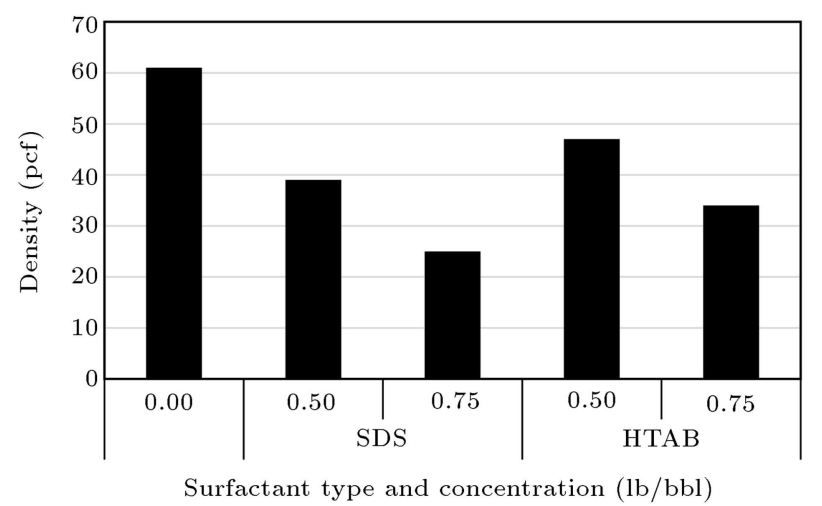

Figure 5. The effect of surfactant type and concentration on the density of CGAs for $2 \mathrm{lb} / \mathrm{bbl}$ solution of XG base fluid.

aspects of any drilling fluid. The viscosity, quantity, and size of aphronized fluid can affect the amount of filtration loss. Previous studies have revealed that by increasing surfactant and polymer concentrations, the filtration loss is reduced in CGA fluids. Increasing surfactant concentration will increase the amount of micro bubbles, which act like a solid free bridging material and reduce filtration loss. On the other hand, by increasing polymer con- 


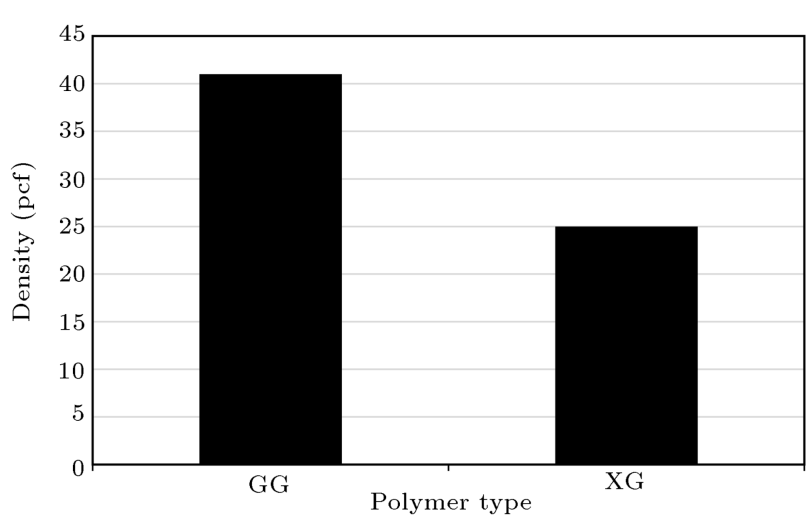

Figure 6. Effect of polymer type on CGA density at 0.75 $\mathrm{lb} / \mathrm{bbl} \mathrm{SDS}$ and $2 \mathrm{lb} / \mathrm{bbl}$ polymer concentrations.

centration, the viscosity of aphronized fluid increases, which has a direct effect on reduction of filtration loss.

The effect of surfactant type on filtration loss is illustrated in Figure 7, where the CGAs are prepared with $2 \mathrm{lb} / \mathrm{bbl}$ solution of XG base fluid. CGA fluids prepared by both surfactants were able to reduce the amount of filtration loss compared to the base fluid. Moreover, as was expected, the CGA fluid prepared by SDS had a better performance in controlling filtration loss, which is in complete agreement with results of rheology and density. Because SDS is able to produce higher viscosity and lower density (i.e., higher number of aphrons), it has better control on filtration loss.

Effect of polymer type and concentration on filtration loss of aphronized fluids is illustrated in Figure 8. Filtration loss increased from $19 \mathrm{~mL} / 30 \mathrm{~min}$ for CGA fluid prepared by $2.0 \mathrm{lb} / \mathrm{bbl} \mathrm{XG}$ to $33 \mathrm{lb} / \mathrm{bbl}$ for 2.0 $\mathrm{lb} / \mathrm{bbl} \mathrm{GG}$, which shows that $\mathrm{XG}$ is greatly superior to GG in the case of filtration control. In addition, filtration loss of CGA fluid prepared by $1.5 \mathrm{lb} / \mathrm{bbl}$ $\mathrm{XG}$ and $0.5 \mathrm{lb} / \mathrm{bbl} \mathrm{GG}$ was nearly same as that of CGA fluid prepared by $2.0 \mathrm{lb} / \mathrm{bbl}$ XG (Figure 8). In the 5 CGA-based fluids prepared by formulating different concentrations of $\mathrm{XG}$ and $\mathrm{GG}$, the effect of aphron micro bubbles in the fluid based on filtration loss was found to be significant. In all samples, after aphronization, filtration loss reduction in XG was more than that in GG. This is due to the rapid flow of the micro bubbles relative to the base fluid (i.e., bubbly flow) and also the capability of XG aphrons to create an external bridge by their accumulation [51]. Increasing $\mathrm{XG}$ concentration also reduces the amount of filtration loss in comparison to the GG, but an acceptable viscosity for controlling fluid loss is essential. Besides, the shear viscosity is too high for pumps and handling of the operations.

\section{Conclusions}

In this study, different formulations of aphron-based

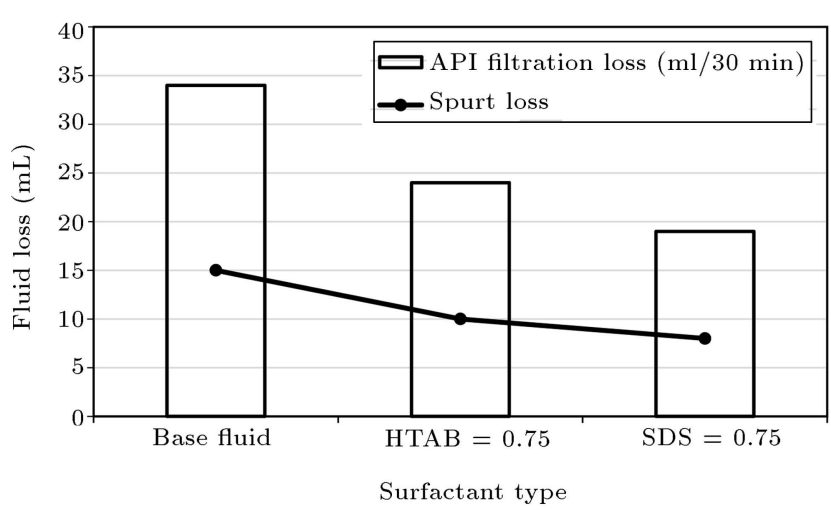

Figure 7. Effect of surfactant type on API filtration loss.

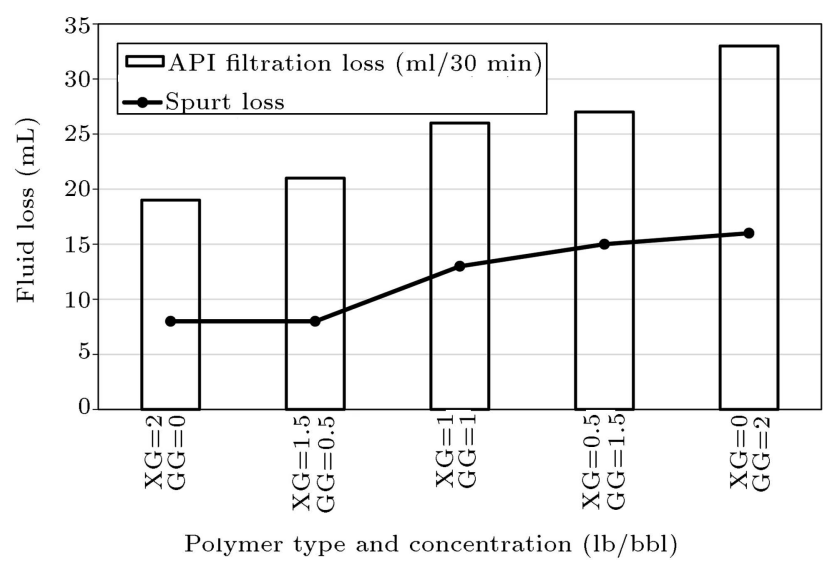

Figure 8. Effect of polymer type and concentration on filtration loss of the prepared CGA fluid by $0.75 \mathrm{lb} / \mathrm{bbl}$ SDS.

drilling fluids were tested. Effect of polymer as well as surfactant type and concentration on the main physicochemical properties of aphronized fluids, such as density, rheological properties, bubble size distribution, and filtration properties, was investigated. In order to investigate the filtration behavior of different samples and rheology tests, density measurement and optical microscopy to visualize the bubble sizes and quantities were conducted. The following conclusions can be drawn from the experimental data:

- As the polymer concentration increased at constant surfactant concentration (for both XG and GG), the viscosity and density of the aphronized fluid increased while the volume of filtration loss and average bubble size decreased (i.e., improvement in rheological fluid properties);

- As the surfactant concentration increased at constant polymer concentration (for both SDS and HTAB), the viscosity increased while the density, filtration volume, and average bubble size decreased due to the generation of more micro bubbles;

- For the same type and concentration of surfactant (SDS or HTAB), XG shows better rheological and 
filtration properties than GG. This means that XG is a better choice to generate CGA, but the cost is a crucial factor. Thus, a $3: 1$ ratio of $\mathrm{XG} / \mathrm{GG}$ is recommended to reduce the cost while maintaining the properties at the same level;

- For the same type and concentration of polymer (XG or GG), the anionic surfactant (SDS) shows better rheological and filtration properties than the cationic one (HTAB) to generate the CGA;

- To obtain better rheological and filtration properties (i.e., to improve conditions of CGA fluids), the $\mathrm{pH}$ should be kept somewhere around 9 (i.e., moderate alkaline media).

\section{Nomenclature}

$\begin{array}{ll}\text { CGA } & \text { Colloidal Gas Aphron } \\ \text { CMC } & \text { Critical Micelle Concentration } \\ \text { MWD } & \text { Measurement While Drilling } \\ \text { API } & \text { American Petroleum Institute } \\ \text { pcf } & \text { Pound per cubic foot } \\ \tau & \text { Shear Stress (SS) } \\ \gamma & \text { Shear Rate (SR) } \\ \tau_{0} & \text { Yield Point (YP) } \\ n & \text { Power law index } \\ K & \text { Consistency index } \\ \text { AV } & \text { Apparent Viscosity } \\ \text { PV } & \text { Plastic Viscosity } \\ \text { GS } & \text { Gel Strength }\end{array}$

\section{References}

1. Ivan, C.D., Quintana, J.L. and Blake, L.D. "Aphronbase drilling fluid: Evolving technologies for lost circulation control", Proceedings of SPE Annual Technical Conference and Exhibition, New Orleans, Louisiana (2001).

2. Brookey, T. "Micro-bubbles: New aphron drill-in fluid technique reduces formation damage in horizontal wells", Proceedings of SPE Formation Damage Control Conference, Lafayette, Louisiana (1998).

3. Sebba, F., Foams and Biliquid Foams-Aphrons, Wiley, New York, First Edition (1987).

4. Lye, G.J. and Stuckey, D.X. "Structure and stability of colloidal liquid aphrons", Colloids and Surfaces A: Physicochemical and Engineering Aspects, 131, pp. 119-136 (1998).

5. Deng, T., Dai, Y. and Wang, J. "A new kind of dispersion-colloidal emulsion aphrons", Colloids and Surfaces A: Physicochemical and Engineering Aspects, 266, pp. 97-105 (2005).
6. Ziaee, H., Arabloo, M., Ghazanfari, M.H. and Rashtchian, D. "Herschel-Bulkley rheological parameters of lightweight colloidal gas aphron (CGA) based fluids", Chemical Engineering Research and Design, 93, pp. 21-29 (2015).

7. Ramirez, F., Greaves, R. and Montilva, J. "Experience using microbubbles-aphron drilling fluid in mature reservoirs of Lake Maracaibo", Proceedings of International Symposium and Exhibition on Formation Damage Control, Lafayette, Louisiana (2002).

8. Rea, A.B., Alvis, E.C., Paiuk, B.P., Climaco, J.M., Vallejo, M., Leon, E. and Inojosa, J. "Application of aphrons technology in drilling depleted mature fields", Proceedings of SPE Latin American and Caribbean Petroleum Engineering Conference, Port-ofSpain, Trinidad and Tobago (2003).

9. Hashim, M.A., Mukhopadhyay, S., Gupta, B.S. and Sahu, J.N. "Application of colloidal gas aphrons for pollution remediation", Journal of Chemical Technology and Biotechnology, 87(3), pp. 305-324 (2012).

10. Alizadeh, A. and Khamehchi, E. "Mathematical modeling of the colloidal gas aphron motion through porous medium, including colloidal bubble generation and destruction", Colloid and Polymer Science, 294, pp. 1075-1085 (2016).

11. Growcock, F.B., Khan, A.M. and Simon, G.A. "Application of water-based and oil-based aphrons in drilling fluids", Proceedings of International Symposium on Oilfield Chemistry, Houston, Texas (2003).

12. Molaei, A. and Waters, K.E. "Aphron applications A review of recent and current research", Advances in Colloid and Interface Science, 216, pp. 36-54 (2015).

13. Moshkelani, M. and Chalkesh Amiri, M. "An insight into colloidal gas aphron drainage using electrical conductivity measurement", Iranian Journal of Chemistry and Chemical Engineering, 27(3), pp. 63-68 (2008).

14. Growcock, F. "Enhanced wellbore stabilization and reservoir productivity with aphron drilling fluid technology", Final report, DOE Award Number DE-FC2603NT42000 (2004)

15. Oyatomari, C., Orellán, S., Alvarez, R. and Bojani, R., Application of Drilling Fluid System Based on Air Microbubbles as an Alternative to Underbalance Drilling Technique in Reservoir B-6-X.10-Tia Juana, Lake Maracaibo, International Association of Drilling Contractors, Madrid, Spain (2002).

16. Roy, D., Valsaraj, K.T. and Kottai, S.A. "Separation of organic dyes from wastewater by using colloidal gas aphrons", Separation Science and Technology, 27(5), pp. 573-588 (1992).

17. Longe, T.A. "Colloidal Gas Aphrons: Generation, Flow Characterization, and Application in Soil and Groundwater Decontamination", Ph.D. Thesis, Virginia Polytechnic Institute and State University, Virginia (1989).

18. Arabloo Nareh'ei, M., Pordel Shahri, M. and Zamani, M. "Preparation and characterization of colloidal gas 
aphron based drilling fluids using a plant-based surfactant", Proceedings of SPE Saudi Arabia Section Technical Symposium and Exhibition (2012).

19. Amiri, M.C. and Woodburn, E.T. "Method for the characterisation of colloidal gas aphron dispersions", Chemical Engineering Research and Design, 68, pp. 154-160 (1990) .

20. Save, S.V., Pangarkar, V.G. and Vasanth Kumar, S. "Intensification of mass transfer in aqueous two-phase systems", Biotechnology and Bioengineering, 41(1), pp. 72-78 (1993).

21. Chaphalkar, P.G. "Characterization and application of colloidal gas aphrons for groundwater remediation", Ph.D. Thesis, Baton Rouge, Louisiana State University (1994).

22. Hashim, M.A., Dey, A., Hasan, S. and Sen Gupta, B. "Mass transfer correlation in flotation of palm oil by colloidal gas aphrons", Bioprocess Engineering, 21, pp. 401-404 (1999).

23. Hashim, M.A., Kumar, S.V. and Sen Gupta, B. "Particle-bubble attachment in yeast flotation by colloidal gas aphrons", Bioprocess Engineering, 22, pp. 333-336 (2000).

24. Bjorndalen, N. and Kuru, E. "Physico-chemical characterization of aphron-based drilling fluids", Journal of Canadian Petroleum Technology, 47(11), pp. 15-21 (2008).

25. Dai, Y. and Deng, T. "Stabilization and characterization of colloidal gas aphron dispersions", Journal of Colloid and Interface Science, 261, pp. 360-365 (2003).

26. Caenn, R. and Chillingar, G.V. "Drilling fluids: State of the art", Journal of Petroleum Science and Engineering, 14, pp. 221-230 (1996).

27. Navarrete, R.C., Dearing, H.L., Constien, V.G., Marsaglia, K.N., Seheult, J.M. and Rodgers, P.E. "Experiments in fluid loss and formation damage with Xanthan-based fluids while drilling", Proceedings of IADC/SPE Asia Pacific Drilling Technology, Kuala Lumpur, Malaysia (2000)

28. M'bodj, O., Kbir Ariguib, N., Trabelsi Ayadi, M. and Magnin, A. "Plastic and elastic properties of the systems interstratified clay-water-electrolyte-xanthan", Journal of Colloid and Interface Science, 273, pp. 675684 (2004).

29. Arabloo, M., Pordel Shahri, M. and Zamani, M. "Characterization of colloidal gas aphron fluids produced from a new plant-based surfactant", Journal of Dispersion Science and Technology, 34(5), pp. 669-678 (2013).

30. Spinelli, L.S., GNeto, G.R., Freire, L.F.A., Monteiro, V., Lomba, R., Michel, R. and Lucas, E. "Syntheticbased aphrons: Correlation between properties and filtrate reduction performance", Colloids and Surfaces A: Physicochemical and Engineering Aspects, 353, pp. 57-63 (2010).
31. Kok, M.V. "Statistical approach of two-three parameters rheological models for polymer type drilling fluid analysis, Energy Sources", Part A: Recovery, Utilization, and Environmental Effects, 32, pp. 336345 (2009).

32. Zamora, M., Jefferson, D.T. and Powell, J.W. "Holecleaning study of polymer-based drilling fluids", Proceedings of SPE Annual Technical Conference and Exhibition, Houston, Texas (1993).

33. Kelessidis, V. and Maglione, R. "Modeling rheological behavior of bentonite suspensions as Casson and Robertson-Stiff fluids using Newtonian and true shear rates in Couette viscometry", Powder Technology, $\mathbf{1 6 8}$ pp. 134-147 (2006).

34. Kelessidis, V., Maglione, R., Tsamantaki, C. and Aspirtakis, Y. "Optimal determination of rheological parameters for Herschel-Bulkley drilling fluids and impact on pressure drop, velocity profiles and penetration rates during drilling", Journal of Petroleum Science and Engineering, 53, pp. 203-224 (2006).

35. Bailey, W.J. and Weir, S. "Investigation of methods for direct rheological model parameter estimation", Journal of Petroleum Science and Engineering, 21, pp. 1-13 (1998).

36. Chen, Z., Ahmed, R.M., Miska, S.Z., Takach, N.E., $\mathrm{Yu}$, M. and Pickell, M.B. "Rheology and hydraulics of polymer (HEC) based drilling foams at ambient temperature conditions", SPE Journal, 12, pp. 100107 (2007).

37. Hamida, T., Kuru, E. and Pickard, M. "Rheological characteristics of aqueous waxy hull-less barley (WHB) solutions", Journal of Petroleum Science and Engineering, 69, pp. 163-173 (2009).

38. Khalil, M., Jan, B.M. and Raman, A.A.A. "Rheological and statistical evaluation of nontraditional lightweight completion fluid and its dependence on temperature", Journal of Petroleum Science and Engineering, 77, pp. 27-33 (2011).

39. Arabloo, M. and Pordel Shahri, M. "Experimental studies on stability and viscoplastic modeling of colloidal gas aphron (CGA) based drilling fluids", Journal of Petroleum Science and Engineering, 113, pp. 8-22 (2014).

40. Bjorndalen, N. and Kuru, E. "Stability of microbubblebased drilling fluids under downhole conditions", Journal of Canadian Petroleum Technology, 47(6), pp. 4047 (2008).

41. Cardoso, J.J.F., Spinelli, L.S., Monteiro, V., Lomba, R. and Lucas, E.F. "Influence of polymer and surfactant on the aphrons characteristics: Evaluation of fluid invasion controlling", Express Polymer Letters, 4, pp. 474-479 (2010).

42. Ahmadi, M.A., Galedarzadeh, M. and Shadizadeh, S.R. "Colloidal gas aphron drilling fluid properties generated by natural surfactants: Experimental investigation", Journal of Natural Gas Science and Engineering, 27, pp. 1109-1117 (2015). 
43. Spinelli, L., Bezerra, A., Aquino, A., Lucas, E., Monteiro, V., Lomba, R. and Michel, R. "Composition, size distribution and characteristics of aphron dispersions", Macromolecular Symposia, 245/246, pp. 243249 (2006).

44. Feng, W., Singhal, N. and Swift, S. "Drainage mechanism of microbubble dispersion and factors influencing its stability", Journal of Colloid and Interface Science, 337, pp. 548-554 (2009).

45. Zhao, J., Pillai, S. and Pilon, L. "Rheology of colloidal gas aphrons (microfoams) made from different surfactants", Colloids and Surfaces A: Physicochemical and Engineering Aspects, 348, pp. 93-99 (2009).

46. MacPhail, W.F.P., Cooper, R.C., Brookey, T., Robinson, R. and Paradis, J. "Adopting aphron fluid technology for completion and workover applications", Proceedings of SPE International Symposium and Exhibition on Formation Damage Control, Lafayette, Louisiana (2008).

47. Roy, D., Kongara, S. and Valsaraj, K.T. "Application of surfactant solutions and colloidal gas aphron suspensions in flushing naphthalene from contaminated soil matrix", Journal of Hazardous Materials, 42, pp. 247-263 (1995).

48. Wan, J., Veerapaneni, S., Gadelle, F. and Tokunaga, T.K. "Generation of stable microbubbles and their transport through porous media", Water Resources Research, 37, pp. 1173-1182 (2001).

49. Li, X., Thompson, J.G. and Liu, K. "Reduction of amine emissions from an aqueous amine carbon dioxide capture system using charged colloidal gas aphrons", US Patent No. 20160082384 (2016).

50. Jauregi, P., Gilmour, S. and Varley, J. "Characterisation of colloidal gas aphrons for subsequent use for protein recovery", Chemical Engineering Journal, 65, pp. 1-11 (1997).

51. Arabloo, M. and Pordel Shahri, M. "Effect of surfactant and polymer on the characteristics of aphron- containing fluids", The Canadian Journal of Chemical Engineering, 94, pp. 1197-1201 (2016).

52. Bjorndalen, N.N. "A study of the rheology, stability and pore blocking ability of aqueous", Ph.D. Thesis, Edmonton, Alberta (2010).

\section{Biographies}

Me'raj Heidari obtained his BS and MS degrees in Petroleum Engineering from the Department of Petroleum Engineering, Ahwaz Faculty of Petroleum Engineering, Petroleum University of Technology, Iran. His research interests include preparations of drilling fluids, and characterization and evaluations in the field of petroleum engineering.

Khalil Shahbazi is an Assistant Professor of Petroleum Engineering in the Ahwaz Faculty of Petroleum Engineering, Petroleum University of Technology, Iran. His current research interests include conventional and underbalanced drilling, drilling fluids characterization, applications of finite difference in wellbore flow modeling, rheology of non-Newtonian fluids, and acidizing and hydraulic fracturing of wells.

Moslem Fattahi obtained his BS degree in Chemical Engineering in 2006 from Razi University, Kermanshah, Iran, and his MS and $\mathrm{PhD}$ degrees in 2008 and 2013 from the Department of Chemical and Petroleum Engineering at Sharif University of Technology, Tehran, Iran. Now, he is an a Assistant Professor of Chemical Engineering in the Abadan Faculty of Petroleum Engineering, Petroleum University of Technology, Iran. His main research interests include process modeling, reaction engineering, catalysts and nano-materials (mostly CNT and graphene-based) preparation, characterization and evaluations in the field of chemical engineering, petroleum refining, and drilling engineering. 